\title{
ENSAIO SOBRE UMA PRÁTICA EDUCATIVA INSTITUINTE: A ESCOLA COMO LUGAR DE PRODUÇÃO CULTURAL \\ TEST ON AN INSTITUTIVE EDUCATIONAL PRACTICE: THE SCHOOL AS A PLACE OF CULTURAL PRODUCTION
}

\author{
Ana Paula Mello ${ }^{20}$ \\ Sérgio Silva ${ }^{21}$
}

\begin{abstract}
Resumo
Este artigo é um ensaio que consiste na defesa da ideia de que a escola é um lugar de produção de cultura. Recorremos ao debate realizado no campo do currículo, levando em conta que ao pensarmos projetos para a escola nos deparamos com as intenções que definem a organização do currículo escolar. Desse modo, compreendemos que as intenções presentes no cotidiano escolar não podem ficar restritas a função de prescrever conteúdos. Baseados em práticas educativas da educação patrimonial realizadas no projeto instituinte desenvolvido na Escola Municipal Levi Carneiro, defendemos a ideia de que a escola, ao colocar em prática projetos que dialogam com símbolos de culturas não-hegemônicas, percorre caminhos pelos quais os sentidos amplamente difundidos no cotidiano escolar não conseguem trilhar.
\end{abstract}

Palavras-Chave: Currículo. Prática educativa. Educação patrimonial.

\begin{abstract}
This article is an essay to support the idea that school is a place for culture production. We have considered the discussion in the school curriculum field, taking into account that, when we think about school projects, we deal with intentions that define the organization of school curriculum. Therefore, we understand that the intention in the school routine can't be restricted to school subjects. Based on educational practices of the Heritage Education developed at Escola Municipal Levi Carneiro, we defend the idea that school, when putting in practice projects which deal with non-hegemonic culture symbol, establishes goals which can't be achieved by deeply rooted meanings of everyday school.
\end{abstract}

Keywords: Curriculum. Educational practices. Heritage education.

\footnotetext{
${ }^{20}$ Graduada em Geografia pela UERJ, mestre em Arqueologia pela UFRJ. Professora de Geografia da Escola Municipal Levi Carneiro, linha de pesquisa: educação patrimonial, E-mail: aptmellolevi@gmail.com.

${ }^{21}$ Graduado em Pedagogia pela UERJ, mestre em Educação pela UERJ. Pedagogo da Escola Municipal Levi Carneiro, linha de pesquisa: currículo, E-mail:sergirafael@yahoo.com.br.
} 


\section{Introdução}

O objetivo deste trabalho é tratar da prática educativa norteadora do projeto instituinte Arqueologia e educação patrimonial: a participação da Escola Municipal Levi Carneiro na preservação do patrimônio arqueológico da praia de Itaipu-Niterói. O projeto foi realizado no ano escolar de 2016, tendo como referência práticas educativas que estabeleciam conexões entre arqueologia, educação patrimonial e geografia. A iniciativa de apresentar aos alunos uma parte do patrimônio cultural da cidade de Niterói foi fundamentada em duas ideias principais. Primeiro, despertar o sentimento de preservação e valorização do bem cultural, contribuindo para formar indivíduos que tenham contato com práticas educativas capazes de fortalecer a identidade cultural local, conhecendo patrimônio natural e cultural de uma região muito próxima à escola. Segundo, afirmar que a escola é um lugar de produção cultural.

As ideias norteadoras do projeto resultam de uma mescla entre elementos da perspectiva pós-estrutural do currículo com elementos oriundos da abordagem crítica. Mesclamos elementos de perspectivas teóricas diferentes porque não temos a intenção de fixar um único sentido para o processo educativo realizado no projeto. Cabe ressaltar, as práticas educativas realizadas no decorrer do projeto consideraram que o currículo escolar assume diferentes sentidos ${ }^{22}$ para a comunidade escolar.

Dessa forma, ao apresentarmos aspectos do funcionamento de atividades educativas do projeto instituinte vivenciado na Escola Municipal Levi Carneiro, consideramos que o currículo escolar é composto por uma multiplicidade de intenções que podem ser reelaboradas na circunstância em que elegemos componentes de um projeto curricular. Defendemos que o currículo escolar é constituído por diferentes elementos culturais. Neste contexto, entendemos que as diferentes culturas que circulam no cotidiano escolar não podem ser sintetizadas na ideia de que o conhecimento escolar é universal e homogêneo. Pensar dessa forma remete ao

\footnotetext{
${ }^{22}$ Considerar diferentes sentidos para o currículo escolar é possível porque, tal como Elizabeth Macedo (2006), entendemos que podemos falar "de um currículo que é projetado em nossas falas e que é diferente para cada um de nós, sem generalizar, mas também sem particularizar. Não se trata de um ente abstrato, mas de um híbrido de minhas/nossas memórias e experiências" (MACEDO, 2006, p. 288).
} 


\section{RevistAleph}

caráter prescritivo de organização do currículo que torna inviável considerar a escola como um lugar de produção de cultura.

Nesse sentido, de forma geral, a seguir, expomos indicações inicias do debate realizado no campo curricular com o objetivo de afirmamos que um projeto curricular baseado na prescrição de conteúdos curriculares universais fixa sentidos à prática educativa limitando-a a repetição de intenções que dialogam somente com discursos provenientes da cultura hegemônica. Em seguida, descreveremos práticas educativas do projeto instituinte supracitado que ensaiaram dialogar com símbolos de uma cultura não-hegemônica.

\section{Trilhando pelas fronteiras na área do currículo}

Incialmente, voltamos a nossa atenção para questionar a unidade do conhecimento escolar, uma unidade baseada no entendimento de que existe um conhecimento homogêneo. Neste sentido, se faz necessário conceituar o campo de organização do conhecimento escolar, a partir dos autores Ivor Goodson (1995) e César Coll (1996) e, em seguida, baseados em Elizabeth Macedo (2006), defenderemos que a escola é um lugar de produção de cultura.

Encontramos em Goodson (1995) e Coll (1996) uma preocupação em criticar o caráter prescritivo de organização do conhecimento escolar. Prescrição de conteúdos que, via de regra, desconsidera as condições cotidianas de organização do currículo. Isto porque a preocupação com o estabelecimento de metas, e em seguida, o alcance das metas estabelecidas, coloca-se "muito acima da discussão sobre currículo tal como existe e é correntemente realizado" (GOODSON, 1995, p.52).

A abordagem prescritiva, ao considerar o conhecimento escolar como uma totalidade, permite que coisas diversas sejam tratadas da mesma forma, e que o entendimento do que vem a ser o conhecimento escolar guarde aquilo que se repete, por meio de uma generalização. O desdobramento desta postura no plano de análise curricular permite que o conhecimento escolar se relacione, por exemplo, com teorias científicas ou correntes filosóficas da mesma forma. A generalização da abordagem 
prescritiva possui a capacidade de desprezar a diversidade porque tende a guardar aquilo que é recorrente.

Segundo Coll (1996), os propósitos e as metas na discussão curricular aparecem no momento de definir a organização de um currículo. Neste momento, "uma das tarefas do projeto curricular é proceder à análise, classificação, identificação e formulação das intenções que presidem o projeto educacional” (COLL, 1996, p. 67). No entanto, é importante ressaltar que existe uma multiplicidade de intenções presentes no momento de elaboração de um projeto curricular, multiplicidade que não pode ser ignorada, porque ao ignorá-la reduzimos os diferentes problemas, que de alguma forma se relacionam entre si, a uma homogeneidade.

Esta redução, a nosso ver, se confunde com duas ações que permeiam o processo de elaboração curricular. As ações, segundo Coll (1996), são a organização e a seqüenciação temporal dos conteúdos curriculares. Porém, Coll (1996) não problematiza a questão da multiplicidade de intenções presentes no momento de elaboração de um projeto curricular com a necessidade de organização e seqüenciação temporal deste projeto. Os indícios desta questão aparecem sem serem problematizados no texto que utilizamos como base para o presente trabalho,

Psicologia e currículo: uma aproximação psicopedagógica à elaboração do currículo escolar. Neste texto, César Coll desdobra a multiplicidade de intenções de um projeto curricular em dois aspectos: primeiro, o grau de concretização das intenções educativas; segundo, as vias de acesso na concretização das intenções educativas.

Ao aprofundar estes dois aspectos, Coll (1996) delimita a articulação entre os resultados da aprendizagem, os conteúdos sobre os quais a aprendizagem versa, e às próprias atividades de aprendizagem. Coll identifica esta articulação porque alguns autores, - De Corte et alli (1979), Romiszonwski (1981) e Hameline (1979) -, ao explicarem formas de organização curricular, fundamentam a explicação em pontos que se articulam. Conforme De Corte et ali, "Num extremo, com as formulações muito abstratas sobre as mudanças que a educação formal tenta promover nos alunos, temos os objetivos gerais" (apud COLL, 1996, p.68). Os objetivos gerais mantêm uma 


\section{RevistAleph}

relação estreita com a formulação de objetivos concretos ou objetivos de aprendizagem.

Assim, por exemplo, Romiszowski (1981) denomina finalidade, meta ou propósito educativo um enunciado geral sobre as intenções educativas; no outro extremo, o objetivo de instrução designa um enunciado preciso sobre as intenções educativas; os objetivos de instrução derivam das finalidades educativas graças a uma série de esforços sucessivos de concretização e especificação (COLL, 1996, p.68).

Conforme Coll (idem), Hameline (1979) coloca em um extremo as finalidades que são "afirmações de princípio através das quais a sociedade (ou grupo social) identifica e veicula seus valores, e que proporcionam linhas mestras a um sistema educacional" (apud COLL, 1996, p. 69). Entre as finalidades e os objetivos específicos ou operacionais Hameline (1979) acrescenta metas educacionais e objetivos gerais. Ao apresentar os conceitos destes autores, Coll (1996) nos indica que o esforço realizado por esta gama de terminologias consiste em conseguir identificar o grau de concretização das intenções educativas. Como se fosse possível, a partir do esforço de articular generalizações (objetivos gerais ou finalidades) e especificidades (objetivos específicos), precisar o grau de concretização das intenções educativas. Este esforço de precisão limita práticas educativas que estejam preocupadas em dialogar com as culturas locais presentes no contexto social em que uma determinada escola está inserida.

Dessa forma, a urgência dada à organização e à sequenciação de um projeto curricular pode ficar restrita à tarefa de prescrever conteúdos, que podem ser considerados universais porque contêm uma marca,

Trata-se de identificar os processos cognitivos mais importantes na aprendizagem, a fim de confeccionar um repertório de habilidades independentes de conteúdos específicos e, portanto, suscetível de ser aplicado a uma variedade de situações (COLL, 1996, p. 72).

Segundo Coll (1996), identificar os processos cognitivos mais importantes é uma marca da psicologia. Temos, por exemplo, uma preocupação em identificar destrezas cognitivas que possam ser generalizadas. 
Os efeitos desejáveis da educação escolar não devem referir-se tanto à aquisição de itens específicos de conhecimento, ou determinadas pautas de comportamento, quanto à aquisição de destrezas cognitivas que possam generalizar-se e ser aplicadas a uma ampla gama de situações (COLL, 1996, p. 73).

A tendência de isolar características do processo cognitivo que permitam a aquisição de itens específicos de conhecimento contribui para o entendimento de que existe um conhecimento escolar universal, ou seja, que determinados conteúdos são mais eficazes na aquisição de destrezas cognitivas e podem generalizar-se nas diversas práticas pedagógicas escolares. Neste sentido, Goodson (1995) apresenta considerações importantes, que nos indicam o problema de fixar uma prescrição de hábitos intelectuais específicos como metas a serem trilhadas por um projeto curricular.

Os que acreditam em metas educacionais baseadas nas disciplinas são obrigados, em última análise, a se defrontar com a triste verdade de que o mundo da escolarização como correntemente se apresenta desenvolve-se em tal ritmo que o estabelecimento de metas é difícil e os quadros de metas nem sempre são relevantes (GOODSON, 1995, p. 53).

Segundo Goodson (idem), a proposta de organização de um currículo prescritivo, baseada em uma ideia preconcebida de que existe um conhecimento escolar geral, em que diferentes habilidades cognitivas, que foram isoladas e identificadas no plano teórico, conseguem sustentar e dar forma a um conhecimento escolar universal, pode ser superada pela articulação entre teoria-prática. A atenção do pesquisador do campo do currículo precisa se dirigir para o esforço de elaborar uma teoria curricular que não isole em lados opostos a elaboração teórica da prática pedagógica das escolas.

A nossa teoria precisa desenvolver-se a partir do entendimento do currículo tal como é elaborado. Em síntese, não necessitamos de teorias sobre prescrições curriculares, mas de estudos, [...] de teorias sobre elaboração e aplicação de currículo (GOODSON, 1995, p. 55).

A proposta de Macedo (2006) no texto intitulado Currículo como espaço-tempo de fronteira cultural, a nosso ver, desloca a discussão sobre a necessidade de 


\section{RevistAleph}

elaboração de um projeto curricular alicerçado na ideia de que existe um conhecimento escolar homogêneo para " a compreensão da dinâmica do currículo como cultura" (MACEDO, 2006, p. 287). Compreender a dinâmica do currículo como cultura significa abolir as fronteiras que demarcam e colocam em lados opostos as diferenças existentes na escola. Conforme Macedo (idem), "não parece produtivo assumir que esse espaço-tempo do currículo é um lugar de confronto entre culturas com lados definidos" (MACEDO, 2006, p. 287). Para a autora, romper com as fronteiras estabelecidas é um esforço que abre a perspectiva da negociação, mesmo sendo esta uma perspectiva ainda nebulosa. A negociação é um caminho possível para que diferentes tradições culturais possam viver de múltiplas formas.

Nesse sentido, conforme Lopes e Macedo (2011), a perspectiva pós-estrutural no campo do currículo ajuda a produzir sentidos, leituras, análises que questionam/tensionam a contribuição de perspectivas do campo curricular que operam com sentidos gerais de conhecimento escolar. Ao descontruir sentidos fixados e amplamente utilizados no cotidiano escolar, temos a intenção de apontar os limites do discurso hegemônico no campo curricular para entender a produção cultural realizada na instituição escolar a partir dos diferentes discursos que circulam no chão da escola.

Entendemos currículo escolar, com base em Elizabeth Macedo (2006), como um híbrido de memórias e experiências, projetado por falas, que assume sentido diferente para cada um de nós. Pensar o currículo escolar como um híbrido permite admitirmos que o mesmo é composto por diferentes elementos culturais. Nesse sentido, currículo pode ser pensado como espaço-tempo de fronteira cultural, um projeto dinâmico, em que o confronto entre culturas com lados definidos é algo a ser evitado. "Parto do princípio de que o currículo é um espaço-tempo em que sujeitos diferentes interagem, tendo por referência seus diversos pertencimentos, e que essa interação é um processo cultural" (MACEDO, 2006, p. 288).

Pensar o currículo escolar como espaço-tempo de fronteira cultural é ir de encontro as concepções curriculares que fazem uma distinção entre currículo formal e 


\section{RevistAleph}

currículo vivido. Distinções que não são apenas restritas ao campo da didática, mas que influenciam o estudo de políticas e práticas curriculares.

A produção dos currículos formais e a vivência do currículo são processos cotidianos de produção cultural, que envolvem relações de poder tanto em nível macro quanto micro. Em ambos são negociadas diferenças. De ambos participam sujeitos culturais com seus múltiplos pertencimentos (MACEDO, 2006, p. 287).

Ao admitirmos que os currículos escolares são formados por processos de produção cultural, trazemos à tona um duplo movimento narrativo marcado por uma temporalidade continuísta e por uma estratégia performática.

Nesse sentido, a educação apresenta-se e autoriza-se como história, como espaço-tempo da repetição. Essa temporalidade continuísta convive, no entanto, com uma outra temporalidade, que, como Bhaba, chamo de performática. Há na educação um projeto de significação que nega qualquer temporalidade anterior, qualquer referência a um passado essencialmente bom, o que seria a sua própria negação. A tensão entre repetição e performatividade cria uma zona de ambivalência, um espaço-tempo liminar, em que é possível pensar a existência do outro (MACEDO, 2006, p. 290).

Para Macedo (idem), conceber o currículo escolar como espaço-tempo de fronteira cultural nos coloca diante do outro cultural. Desse modo, o outro cultural não é compreendido a partir de culturas legitimadas, como o avesso que impede a temporalidade continuísta de se realizar, mas pode ser pensado a partir da temporalidade performativa. Nesse sentido, o performativo permite que as vozes que não são hegemônicas tenham a possibilidade de orientar suas estratégias para horizontes não-hegemônicos.

Uma temporalidade que, na expressão de Bhabha, é um entre-lugar que permite que as vozes marginais "não mais necessitem dirigir suas estratégias de oposição para um horizonte de 'hegemonia', que é concebido como horizontal e homogêneo (MACEDO, 2006, p. 289).

A perspectiva pós-estrutural ao entender o currículo como lugar de produção cultural tem a intenção de pensar a diferença como um discurso relacional e não como diversidade. Nessa perspectiva, o outro cultural não é concebido como o outro multicultural. As produções culturais no currículo escolar, entendidas como híbrido cultural, fortalecem tramas de certos grupos e potencializam resistências. 
O entendimento do currículo como híbrido cultural parece-me crucial para pensar a diferença, não como diversidade (BURBULES, 2003), mas como um discurso relacional em que o próprio sistema de sua representação está em questionamento. Como defende Skliar (2002), um outro que, ao contrário do outro multicultural, é político, "que não vive somente para contestar o malefício, que não se alinha facilmente a uma cultura que pode ser ordenada como múltipla, que não pode ser reduzido [...] a uma ação apenas relacional e comunicativa" (p. 202). Para pensar a diferença, passo a tratar, portanto, do currículo como espaço-tempo híbrido, de fronteira entre culturas que se legitimam de forma diferenciada (MACEDO, 2006, p. 290).

Em resumo, consideramos que o conhecimento escolar transmitido/ensinado nas disciplinas previstas no currículo não é homogêneo. Sendo assim, a seleção de conteúdos que podem ser generalizados com o objetivo de fazer com que os alunos adquiram determinadas destrezas cognitivas, por meio de práticas educativas controladas, é um processo que não considera a diferença cultural com discurso relacional.

A seguir, abordaremos o projeto que inseriu uma cultura não hegemônica no cotidiano de uma escola da rede pública municipal de educação da cidade de Niterói. No projeto instituinte da Escola Municipal Levi Carneiro tratamos de símbolos da cultura denominada Sambaquis ${ }^{23}$.

\section{Produção cultural na escola: projeto instituinte mobilizando conhecimentos não previstos no currículo escolar.}

Considerar que a escola é um lugar de produção cultural pressupõe adotarmos práticas educativas que tentem romper com atividades realizadas no seu cotidiano escolar que estão presas a elementos da cultura hegemônica. Nesse percurso, um caminho possível para que diferentes tradições culturais possam emergir no cotidiano escolar é adotar práticas educativas baseadas em conteúdos curriculares não prescritos no currículo formal.

\footnotetext{
${ }^{23}$ Sambaquis são sítios arqueológicos de grupos que habitaram o litoral brasileiro há oito mil anos antes do tempo presente. Esses sítios têm como características presença de conchas, peixes e sepultamentos em sua formação.
} 
Nesse sentido, ao contrário da abordagem prescritiva, entendemos que o conhecimento escolar não necessita ser tratado como uma generalização. Desse modo, alguns temas adotados no currículo podem ser escolhidos pelos profissionais da educação estabelecendo um diálogo com culturas locais que compõem o universo cultural da região na qual a escola está inserida.

Então, o esforço realizado na prática educativa ao considerar a escola como um lugar de produção cultural não se limita a tentar articular generalizações e especificidades, objetivos gerais e objetivos específicos, previstos no currículo do ensino fundamental. Procuramos mobilizar conhecimentos/saberes em diálogo com elementos de culturas não hegemônicas, em processo que traz para o cotidiano escolar a possibilidade de conteúdos curriculares operarem sentidos não fixados pela cultura hegemônica.

Os sentidos mobilizados por conhecimentos/saberes de grupos culturais que não compõem os conteúdos do currículo formal podem ser encarados como uma tentativa de não colocar em lados opostos diferentes culturas. Baseados em Macedo (2006), entendemos que algumas fronteiras estabelecidas no currículo escolar podem ser desconstruídas. Descontruir os sentidos fixados e amplamente utilizados no cotidiano escolar é um movimento que permite identificarmos a escola como um lugar de produção cultural, ao invés de a considerarmos, somente, como um lugar que reproduz práticas educativas baseadas na cultura hegemônica.

A nosso ver, o projeto instituinte Arqueologia e educação patrimonial: a participação da Escola Municipal Levi Carneiro na preservação do patrimônio arqueológico da praia de Itaipu-Niterói procurou desenvolver práticas educativas que trouxessem para o cotidiano escolar símbolos da cultura de grupos que habitaram o litoral brasileiro antes dos colonizadores europeus. Dessa forma, entendemos que a realização do projeto instituinte sobre os Sambaquis contribuiu para inserir, em atividades curriculares previstas na disciplina de geografia conhecimentos/saberes sobre a ocupação do espaço do Brasil. São conhecimentos/saberes que não cabem na ideia de ocupação a partir do descobrimento desse território por povos europeus. 
Abordaremos, a seguir, os contornos que orientaram o desenvolvimento do projeto.

\section{Notas sobre educação patrimonial, arqueologia e geografia}

A escola é responsável não apenas por fornecer informações ou conteúdos formais, mas principalmente por formar cidadãos críticos e conscientes sobre a relevância de suas ações no mundo (FIGUEIRA E MIRANDA, 2012). Ela é o principal lugar de aprendizado, sociabilidade e desenvolvimento cultural, pois na escola os alunos formam sua identidade e estabelecem relações com diferentes grupos sociais, cujo processo de ensino e aprendizagem inclui diversas possibilidades pedagógicas, estimulando um olhar mais abrangente sobre a diversidade cultural humana.

O desenvolvimento de ações pautadas na educação patrimonial é importante, pois favorece a conscientização sobre a responsabilidade individual no lugar onde vivemos e na sociedade como um todo, a construção de identidade e memórias coletivas, além de valorizar ações que fortalecem a prática da cidadania.

Conforme Horta et alli (1999), a educação patrimonial consiste em provocar situações de aprendizado sobre o processo cultural, seus produtos e manifestações, visando despertar nos alunos o interesse em resolver questões significativas para a sua própria vida pessoal e coletiva.

A educação patrimonial possibilita ao aluno perceber que o patrimônio cultural faz parte da sua própria história. De acordo com Figueira e Miranda (2012), tal percepção the propicia a oportunidade de conhecer e vivenciar os costumes da cultura local construindo laços de afetividade e de solidariedade com as pessoas e o lugar onde vive, dando um novo significado a este. $\mathrm{O}$ acesso ao conhecimento e as vivências relacionadas às diversas manifestações culturais e ao patrimônio cultural nos ajudam no entendimento sobre o que vem a ser patrimônio cultural como prática social. $A$ partir daí são desenvolvidas atividades que permitam que os alunos compreendam a importância da sua valorização e preservação.

O projeto instituinte da Escola Municipal Levi Carneiro foi orientado a partir de uma proposta interdisciplinar. Utilizamos conceitos importantes das áreas da 


\section{RevistAleph}

arqueologia e geografia para nos aprofundarmos sobre os estudos arqueológicos da região de Itaipu e sua Pré-História. Nos encontros, os alunos eram estimulados a fazer uma leitura da realidade estudada e a dar importância ao trabalho de preservação da história de Niterói e a significação afetiva do lugar.

A arqueologia é a ciência que estuda e interpreta a cultura material de grupos que viveram no passado. Segundo Funari (2013), pode ser definida, na origem, como estudo das coisas antigas. $\mathrm{O}$ autor destaca que esta manteve a centralidade do estudo do mundo material, daquilo que pode ser tocado, transformado e feito pelo ser humano, definido, por convenção como cultura material.

A prática arqueológica é ferramenta importante para a descoberta de um passado pré-histórico e para a valorização de símbolos da cultura material nos dias atuais.

A geografia é a ciência que estuda o espaço geográfico, buscando compreender a dinâmica do espaço produzido e transformado direta ou indiretamente pela sociedade. Seu estudo é focado na relação entre seres humanos e a natureza, e o consequente processo de sua organização do espaço a fim de melhorar as relações socio- espaciais. Um dos principais conceitos da geografia é o conceito de lugar. Santos (2012) considera que o lugar é "globalmente ativo" e que "mais importante que a consciência do lugar é a consciência do mundo obtida através dele" (SANTOS, 2012, p.8). Dessa forma, nos detivemos nos espaços utilizados pelos alunos em seu dia-a-dia, considerando as diferentes perspectivas e vivências que um determinado lugar representa para cada indivíduo e o valor do conhecimento do passado para a ressignificação de hábitos culturais e para a preservação do patrimônio cultural.

Ao usarmos fundamentos da geografia e da arqueologia para a concretização do nosso projeto, percebemos que os bens patrimoniais se relacionam com todas as áreas do conhecimento. Assim, o estímulo ao desejo de conhecer e de compreender o desenvolvimento de ações para valorizar e preservar nossos bens culturais e o incentivo a sentimentos de pertencimento a um lugar compõem movimentos essenciais que podem ser trabalhados por diversas áreas do conhecimento. Inclusive, 


\section{RevistAleph}

podendo ser feito por meio de atividades que envolvam toda a comunidade, desenvolvendo um sentimento de afetividade pelos bens culturais locais.

Segundo Funari e Noelli (2002), no que se refere ao passado da civilização brasileira, os últimos 500 anos ocupam quase todas as páginas dos livros didáticos, reduzindo significativamente os milhares de anos da Pré-História a uma pequena introdução. Nossas origens remotas ainda são pouco consideradas. Mesmo que mais de 40 milhões de brasileiros tenham antepassados indígenas, essa herança é pouco reconhecida, embora a Lei no 11.645 , de 10 de março de 2008, tenha contribuído para alterar esse panorama educacional, determinando o ensino das culturas afro-brasileira e indígena nas escolas.

O nosso projeto instituinte propõe a possibilidade de compatibilizar a preservação patrimonial e ambiental ao desenvolvimento sustentável no ambiente escolar. Só é possível gostar e cuidar do que conhecemos. Por esta razão é importante a inserção desse assunto por meio de projetos ou como um tema transversal, visando a construção do conhecimento de forma integrada e interdisciplinar, despertando a comunidade escolar para a compreensão da cultura em que está inserida.

A escola tem como função formar cidadãos que se sintam responsáveis pela preservação da história, do patrimônio e da memória da sociedade da qual fazem parte, de maneira que se apropriem da forma identitária e de pertencimento dos aspectos culturais que a constituem, levando-os a compreender, criticar e a refletir sobre o espaço geográfico em que estão inseridos, relacionando seu lugar com o mundo.

\section{Projeto instituinte na Escola Municipal Levi Carneiro}

As atividades desenvolvidas no Clube de Arqueologia relacionaram educação patrimonial, arqueologia e geografia colocando em funcionamento o projeto instituinte.

A educação patrimonial compreende o conjunto de práticas e experiências voltadas à percepção, ao conhecimento, à apropriação, à compreensão, ao reconhecimento, à 


\section{RevistAleph}

valorização dos bens, tangíveis e intangíveis, de nosso patrimônio cultural (FIGUEIRA e MIRANDA, 2012).

O projeto foi planejado da seguinte forma: a) Aulas teóricas sobre arqueologia, sítios arqueológicos brasileiros, com enfoque nos Sambaquis; b) Debate sobre os temas propostos; c) Visita ao Museu Socioambiental de Itaipu; d) Oficinas de artefatos, escavação e confecção de um sepultamento artificial; e) Apresentação e divulgação do projeto na Feira de Ciência, Tecnologia e Inovação de Niterói.

Atendemos, diretamente, 30 alunos, mas por ser um projeto aberto a todos os alunos da escola, no decorrer da execução das atividades propostas surgiram novos candidatos interessados em participar. Nossos encontros aconteciam às terças-feiras, no contra turno, com duração de aproximadamente 2 horas no laboratório de ciências e, às vezes, na sala de leitura. O projeto teve duração de 5 meses (de maio a outubro).

Nos primeiros encontros, a ideia era investigar a percepção que os alunos tinham sobre cultura, paisagem, lugar e arqueologia. Fizemos um trabalho de contextualização e geramos discussões sobre cultura, bens materiais, imateriais e ambientais, relacionando o presente e o passado, aproximando o novo e o antigo. Para ilustrar as aulas utilizamos imagens da cidade de Niterói e patrimônios culturais da humanidade de diversas partes do mundo. Junto à turma, listamos os principais pontos turísticos, belezas naturais e culturais de Niterói com o objetivo de estimular a curiosidade dos alunos sobre esses lugares e também ter noção de seus conhecimentos sobre o tema. É interessante notar que dentre todos os lugares que os alunos lembraram nesta fase estava a praia de Itaipu. Entretanto, nenhum deles citou o Museu de Itaipu ou o Sambaqui Duna Grande, corroborando a importância de um trabalho alicerçado em educação patrimonial na nossa escola.

Nos encontros seguintes, ao apresentar conceitos referentes a arqueologia e debatermos sobre a pré-história brasileira, pudemos perceber que a única referência que os alunos tinham sobre Pré-História eram os sítios arqueológicos de pintura rupestre. Alguns não tinham conhecimento sobre o assunto, pois entendiam que o início de nossa História compreendia apenas os grupos indígenas ceramistas e os colonizadores portugueses. Os alunos não sabiam da existência dos Sambaquis, grupo 


\section{RevistAleph}

que habitou o litoral brasileiro (inclusive a praia de Itaipu e Camboinhas) há aproximadamente 8 mil anos A.P. Este fato reforça o quanto a história do Brasil colonial é fortemente enfatizada nas aulas de história, novelas e filmes, sem considerar o período e as fases da Pré-História.

A nossa herança cultural Pré-Histórica está representada por fragmentos líticos, remanescentes cerâmicos (na maioria cacos), restos faunísticos, sepultamentos, bem como milhares registros rupestres, dentre outros remanescentes, todos de essencial importância para a produção de conhecimento arqueológico. Entretanto são de difícil sensibilização, sobretudo porque dizem respeito à herança indígena, grupos culturais que, durante toda a formação nacional do estado brasileiro, foram sobrepujados, perseguidos e regenerados, em todos os aspectos de seu modo de vida e cultura (FAGUNDES, 2012).

O Brasil é um país rico em diversidade cultural e natural, mas infelizmente a sociedade não tem acesso aos seus bens patrimoniais. A História brasileira foi moldada sob o olhar de uma elite (religiosa, política ou econômica), e consequentemente, causando a "alienação" das comunidades locais com sua herança cultural (ROBRAHN GONZALEZ, 2006). Portanto, trabalhar com educação patrimonial representa dar um novo significado ao bem cultural antes desconhecido ou desvalorizado, transformandoo em herança nacional.

Neste projeto contamos com a participação efetiva dos alunos. Todos se sentiram estimulados e motivados a participar das discussões e atividades propostas. Em todos os momentos, trabalhamos os seus conhecimentos prévios sobre os assuntos estudados, permitindo uma conexão entre seu universo cultural e os conhecimentos mobilizados pelo projeto.

\section{Atividades práticas}

As atividades práticas e oficinas temáticas têm como objetivo a sensibilização de que cultura, história e o ambiente natural são tesouros regionais fundamentais para a constituição de uma sociedade democrática (FAGUNDES, 2012). A visitação ao Museu Socioambiental de Itaipu foi importantíssima para o nosso trabalho, pois os 


\section{RevistAleph}

alunos puderam conhecer o sítio arqueológico, o museu e todo seu entorno. As atividades fora dos muros da escola nos aproximam dos alunos e nos proporcionam novas experiências.

Realizamos uma visita guiada pelo educador do Museu Socioambiental de Itaipu, momento em que os alunos tiveram a oportunidade de conhecer o museu, o Sambaqui Duna Grande de Itaipu e puderam observar e refletir sobre a região. De Itaipu, enxergamos onde era localizado o Sambaqui de Camboinhas, um dos mais antigos do Brasil, e que infelizmente foi destruído devido a especulação imobiliária no bairro e omissão a respeito do patrimônio arqueológico da região.

Os alunos aprenderam um pouco mais sobre a história da região. A antiga ruína, onde hoje se localiza o museu, no Século XVIII, era a Casa de Recolhimento Santa Tereza, local destinado a abrigar mulheres que pretendiam seguir a vida religiosa, órfãs, mulheres de vida fácil, viúvas, mulheres casadas abandonadas ou aquelas que ali eram deixadas por seus pais ou maridos quando estes saíam em viagem. As meninas demonstraram indignação sobre a forma como as mulheres eram tratadas na época e fizemos um paralelo sobre a atuação da mulher na sociedade atual. Em seguida, visitamos a colônia de pescadores ainda presente na praia e conhecemos um pouco sobre a cultura indígena da região.

Ao final da visita, fomos à exposição Percursos do Tempo Revelando Itaipu e tivemos contato com artefatos líticos dos sambaquis de Itaipu e Camboinhas, a simulação de um sepultamento de sambaquieiro, artefatos em cerâmica, uma canoa do grupo indígena local e material do grupo tradicional pesqueiro. No pátio do museu, os alunos tiveram a chance de conhecer uma oca produzida pelo grupo indígena que ocupou a praia de Camboinhas no ano de 2009 e participaram de uma simulação de escavação.

Após a visita ao museu, conversamos sobre o quanto o trabalho de campo foi importante já que muitos alunos, apesar de frequentarem a praia de Itaipu, nunca haviam visto o museu, alguns sequer haviam entrado em um museu anteriormente. Conversamos sobre a importância de conhecer para preservar o patrimônio cultural e 


\section{RevistAleph}

ambiental e podemos notar que a praia de Itaipu passou a ter um novo significado para eles.

As oficinas foram realizadas no laboratório da própria escola e a visita ao museu serviu como base para produção do nosso acervo. Iniciamos nossas atividades práticas com oficinas de artefatos. No museu, os alunos tiveram contato com diversos tipos de artefatos e puderam discutir sobre seus usos e sobre as dificuldades de produzi-los, especialmente numa realidade sem tecnologia digital como a que os jovens estão acostumados. Em seguida, os alunos escolheram um artefato para reproduzir com massa de modelar, o que requer um pouco de habilidade artística.

A atividade mais esperada pelos alunos foi a participação na oficina de escavação. Baseados no que vimos e participamos no Museu de Itaipu, montamos nossa caixa de escavação. O principal objetivo dessa atividade foi fazer com que os alunos se sentissem arqueólogos. A partir dessa prática pudemos discutir sobre o trabalho do arqueólogo e as técnicas de controle de dados, demonstrando que o trabalho é sistemático, que há metodologia científica envolvida, ao mesmo tempo em que permite o reconhecimento e valorização do patrimônio arqueológico.

Utilizamos uma caixa organizadora plástica com tampa, areia de construção, ossos sintéticos e artefatos produzidos pelos alunos na oficina de artefatos. A oficina de escavação também foi realizada na Feira de Ciência, Tecnologia e Inovação de Niterói. A caixa de escavação ficou visível no estande e a todo momento crianças e jovens pediam para mexer no material e aprender um pouco sobre Arqueologia. Os alunos explicavam como é feito o trabalho do arqueólogo e o quanto é importante o uso de técnicas apropriadas para que não haja grande perda de material e do contexto em que o artefato foi encontrado, para facilitar a pesquisa e a interpretação do sítio arqueológico estudado.

Ao visitar o museu, o que mais despertou interesse e curiosidade nos alunos foi o sepultamento. Desse modo, tivemos a ideia de produzir um sepultamento artificial para apresentar o nosso projeto na Feira de Ciência, Tecnologia e Inovação de Niterói. Para montá-lo, utilizamos uma caixa organizadora (para facilitar o transporte do 


\section{RevistAleph}

material), areia de construção civil, artefato feito por eles com massa de modelar, ossos e crânio artificiais, conchas e ossos de peixes doados pelo próprio museu.

Tentamos reproduzir algo semelhante ao encontrado no museu, porém de acordo com o gosto dos alunos. Eles montaram o sepultamento e depois criaram hipóteses sobre as razões pelas quais determinados elementos foram encontrados e sua disposição no sepultamento. É interessante observar esses jovens pensando sobre arqueologia, criando hipóteses e dando importância aos materiais que foram colocados e a sua disposição no sepultamento. Neste contexto, podemos afirmar que os jovens compreenderam a dinâmica de construir significados culturais a partir de vestígios arqueológicos. Através de interpretações feitas nas atividades desenvolvidas, foi possível ressignificar a praia de Itaipu com ênfase na importância da história regional.

Nossa última atividade prática foi a participação na Feira de Ciência, Tecnologia e Inovação de Niterói. Este é um evento que abrange todas as escolas, públicas e privadas, do município que tenham interesse em ciências e queiram apresentar suas pesquisas e produções culturais realizadas durante o ano. Participar de um evento tão grandioso foi uma experiência fantástica para todos nós. Tivemos contato com trabalhos magníficos e também com diversas realidades escolares. Outro fator valioso foi perceber o entusiasmo dos alunos na culminância do projeto, fora do ambiente escolar, reconhecerem que é possível ensinar/aprender com outros jovens e que há um nicho gigante quando pensamos em atividades culturais e produções científicas.

Para a feira, levamos todos os materiais produzidos nas oficinas. Nosso projeto instigou a curiosidade dos jovens de outras escolas, e seu desconhecimento sobre o tema do nosso trabalho é um fato bastante curioso. Os alunos adoraram poder tocar nos artefatos líticos e discutir sobre suas possíveis funções, produzir artefatos de massa de modelar, sendo a oficina de escavação a mais procurada.

O projeto instituinte da Escola Municipal Levi Carneiro foi uma importante oportunidade de redescobrir e ressignificar a praia de Itaipu para os alunos e para as pessoas da comunidade escolar que tiveram contato com o projeto. Participar da Feira 
de Ciência e Tecnologia de Niterói foi fundamental para a apresentação do nosso projeto e divulgação do patrimônio cultural e natural da cidade de Niterói.

\section{Considerações finais}

Ao trazermos elementos da cultura Sambaqui para o cotidiano da escola, por meio de práticas educativas que relacionaram educação patrimonial, arqueologia e geografia, nos debruçamos sobre aspectos da Pré-História, associando-os a processos sócio históricos da ocupação e uso do espaço regional, destacando relações de grupos humanos com seu ambiente.

As práticas educativas desenvolvidas no projeto instituinte estavam voltadas para mobilizar na comunidade escolar conhecimentos/saberes sobre um bem cultural local, que possui relação com o passado pré-histórico da sociedade brasileira. Nesse sentido, a educação patrimonial surgiu como uma prática capaz de informar e sensibilizar os alunos sobre o patrimônio cultural regional, enfatizando a importância de preservarmos a memória cultural de culturas não-hegemônicas.

Trazer para o cotidiano escolar conteúdos desconsiderados pelo currículo do ensino fundamental foi um exercício que nos fez pensar sobre a perspectiva curricular que compreende o conhecimento escolar como universal. Compreendemos que as intenções do projeto curricular de uma escola não podem ser reduzidas por um processo de generalização que se dedica somente à finalidade de articular objetivos gerais e objetivos específicos da aprendizagem.

Com base em Macedo (2006), entendemos que o conhecimento escolar não é universal. Além disso, práticas educativas que dialogam com culturas que não são abordadas no currículo escolar contribuem para reformular o conhecimento escolar, um processo no qual a cultura hegemônica diminui sua capacidade de atuação, permitindo que outros pontos de vista possam surgir.

Então, concebemos que a perspectiva pós-estrutural do campo do currículo, ao considerar "a intenção [de] que se reformule o conhecimento escolar de modo a favorecer a afirmação das identidades e dos pontos de vista de grupos minoritários" 


\section{RevistAleph}

(MACEDO, 2006, p. 287), permitiu atentarmos para a escola como um lugar de produção cultural.

Ao adotarmos no currículo escolar produções culturais que fortalecem tramas de grupos minoritários, potencializamos resistências porque o outro cultural surge como um discurso relacional e não mais em oposição a tradições culturais hegemônicas. Por fim, ressaltamos que o tratamento linear e universal de coisas diversas desfavorece o debate sobre as formas de articulação de diferentes culturas no currículo escolar e não contribui para fazer da escola uma instituição capaz de produzir cultura.

\section{REFERÊNCIAS}

COLL, César. Psicologia e Currículo: uma aproximação psicopedagógica à elaboração do currículo escolar. São Paulo: Editora Ática, 1996.

FAGUNDES, Marcelo. Arqueologia e educação: programa "Arqueologia e Comunidades" para crianças e adolescentes no Vale do Jequitinhonha, Brasil. Revista Latinoamericana de Ciências Sociais. São Paulo, v. 11, p. 199-216, 2012.

FIGUEIRA, Cristina Reis; MIRANDA, Lilian Lisboa. Educação patrimonial no ensino de História nos anos finais do ensino Fundamental: Conceitos e práticas. São Paulo: Contexto, 2012.

FUNARI, Pedro Paulo Abreu. Arqueologia no Brasil e no Mundo: origens, problemáticas e tendências. Ed. Sociedade Brasileira para o Progresso da Ciência, 2013.

FUNARI, Pedro Paulo; NOELLI, Francisco Silva. A Pré-História do Brasil. São Paulo: Contexto, 2002.

GOODSON, Ivor. Currículo: teoria e história. Rio de janeiro: Vozes, 1995.

HORTA, Maria de Lourdes; GRUNBERG, Evelina; MONTEIRO, Adriane Queiroz. Guia básico de educação patrimonial. Brasília: IPHAN, Museu Imperial, 1999.

LOPES, Alice Casimiro; MACEDO, Elizabeth. Teorias de currículo. São Paulo: Cortez, 2011.

MACEDO, Elizabeth. Currículo como espaço-tempo de fronteira cultural. Revista Brasileira de Educação, São Paulo, v. 11, n. 32, p. 285-296, maio/ago 2006.

ROBRAH-GONZALEZ, Erika Marion. O Programa Arqueológico do Rodoanel Metropolitano de São Paulo, trecho oeste: ciências, preservação e sustentabilidade social. In MORI, Vitor Hugo; SOUZA, Marise Campos de; BASTOS, Rosano Lopes; GALLO, Haroldo (Orgs.). Patrimônio: atualizando o debate. Brasília: IPAHN, 2006.

SANTOS, Milton. A natureza do espaço: Técnica e Tempo. São Paulo: Editora da Universidade de São Paulo, 2012. 